\title{
PENGARUH REWARD DAN PUNISHMENT TERHADAP KINERJA DAN MOTIVASI KARYAWAN PADA CV MEDIA KREASI BANGSA
}

\author{
Adhitomo Wirawan ${ }^{1}$ ) Ismi Nur Afani ${ }^{2}$ ) \\ 1) Prodi Administrasi Bisnis Terapan Politeknik Negeri Batam, email: adhitomo@ polibatam.ac.id \\ 2) Prodi Administrasi Bisnis Terapan Politeknik Negeri Batam, email: isminurafani@gmail.com
}

\begin{abstract}
This study aims to determine the effect of both simultaneously and partially between reward and punishment on employees performance and motivation at CV. Media Kreasi Bangsa. This study used Multiple Linear Regression method, while the sample in this study using probability sampling technique where the sample was taken using proportionate stratified random which amounted to 132 employees. The research instrument used interview, questionnaire, observation, and documentation. The result of this study is the reward variable has a positive effect on the performance of this matter seen from t arithmetic $(2,363)$ bigger than t table $(1,65)$ with significant level $(0,020$ $<0,05)$. Reward variable has a positive effect on this motivation seen from t arithmetic $(4,289)$ bigger than t table $(1.65)$ with significant level $(0,000<0,05)$. There is a simultaneous influence between reward and punishment variable on the performance of this matter seen from $F$ arithmetic $(21,162)$ bigger than $F$ table $(3,07)$ with significant level $(0,000$ $<0,05)$. The punishment variable has a positive effect on the performance of this matter seen from t arithmetic $(5,309)$ bigger than t table (1.65) with significant level $(0,000<0,05)$. The punishment variable has a positive effect on this motivation seen from $t$ arithmetic $(3,587)$ bigger than $t$ table $(1.65)$ with significant level $(0,000<0,05)$. There is simultaneous influence between reward and punishment variables on this motivation seen from $F$ count $(20,557)$ bigger than F table $(3,07)$ with significant level $(0,000<0,05)$.
\end{abstract}

Keywords: Reward, Punishment, performance, motivation

\begin{abstract}
Abstrak
Penelitian ini bertujuan untuk mengetahui pengaruh baik secara simultan maupun parsial antara reward dan punishment terhadap kinerja dan motivasi karyawan pada CV. Media Kreasi bangsa. Penelitian ini menggunakan metode Regresi Linier Berganda, adapun sampel dalam penelitian ini menggunakan teknik sampling probability dimana sampel di ambil dengan menggunakan proportionate stratified random yang berjumlah 132 karyawan. Instrumen penelitian yang digunakan adalah wawancara, kuesioner, observasi, dokumentasi. Hasil penelitian ini adalah variabel reward berpengaruh positif terhadap kinerja hal ini dilihat dari t hitung $(2,363)$ lebih besar dari t tabel $(1,65)$ dengan tingkat signifikan $(0,020<0,05)$. Variabel reward berpengaruh positif terhadap motivasi hal ini dilihat dari t hitung $(4,289)$ lebih besar dari $t$ tabel $(1,65)$ dengan tingkat signifikan $(0,000<0,05)$. Terdapat pengaruh secara simultan antara variabel reward dan punishment terhadap kinerja hal ini dilihat dari F hitung $(21,162)$ lebih besar dari $\mathrm{F}$ tabel $(3,07)$ dengan tingkat signifikan $(0,000<0,05)$. Variabel punishment berpengaruh positif terhadap kinerja hal ini dilihat dari $\mathrm{t}$ hitung $(5,309)$ lebih besar dari t tabel $(1,65)$ dengan tingkat signifikan $(0,000<0,05)$. Variabel punishment berpengaruh positif terhadap motivasi hal ini dilihat dari t hitung $(3,587)$ lebih besar dari t tabel $(1,65)$ dengan tingkat signifikan $(0,000<0,05)$. Terdapat pengaruh secara simultan antara variabel reward dan punishment terhadap motivasi hal ini dilihat dari F hitung $(20,557)$ lebih besar dari F tabel $(3,07)$ dengan tingkat signifikan $(0,000<0,05)$.
\end{abstract}

Kata Kunci: Reward, Punishment, kinerja, motivasi 
Adhitomo \& Ismi, pengaruh reward dan punishment terhadap kinerja dan motivasi ....

\section{PENDAHULUAN}

Sumber Daya Manusia (SDM) merupakan salah satu faktor yang sangat penting dalam suatu perusahaan disamping faktor yang lain seperti modal. Oleh karena itu SDM harus dikelola dengan baik untuk meningkatkan efektivitas dan efisiensi organisasi (Hariandja, 2002). Sebagai salah satu penunjang proses operasional di suatu perusahaan dan didukung dengan sarana dan prasarana serta sumber daya alam yang memadai, akan tetapi tanpa adanya dukungan dari SDM yang berkompetensi dalam kegiatan di suatu perusahaan tidak akan terjalankan dengan baik. Hal ini menandakan bahwasannya peran SDM merupakan kunci utama yang harus diperhatikan. Sebagai kunci utama, SDM akan menentukan keberhasilan pelaksanaan kegiatan di suatu perusahaan. Tuntutan perusahaan untuk memperoleh, mengembangkan dan mempertahankan sumber daya manusia semakin mendesak, sesuai dengan dinamika lingkungan yang selalu berubah. Pentinganya peranan SDM tercermin dari adanya kebutuhan perusahaan untuk membuat strategi manajemen SDM yang setara dengan pentingnya startegi pada bidang lainnya. Di sisi lain CV. Media Kreasi Bangsa merupakan salah satu perusahaan Ritel yang mmiliki sistem reward dan punishment pada perusahaannya. Perusahaan ini bergerak dalam bidang oleh-oleh khas Batam. Dimana reward dan punishment sangat berpengaruh terhadap kinerja dan motivasi karyawan. Sebab keberhasilan karyawan dalam menjalani aktivitasnya tidak terlepas dari masalah reward dan punishment yang tersedia dan memadai diperusahaan tersebut. menurut (Siswanto, 2003), sistem reward yang ditawarkan dan diberikan kepada karyawan meliputi yaitu sistem Penghargaan Intrinsik dan sistem Penghargaan Ekstrinsik.
Sementara itu hukuman dapat diartikan sebagai hukuman atau sanksi.

Menurut Matteson dalam Gania (2006), "Hukuman didefinisikan sebagai tindakan menyajikan konsekuensi yang tidak menyenangkan atau tidak diinginkan sebagai hasil dari dilakukannya perilaku tertentu. Sedangkan menurut Rivai (2013) jenisjenis hukuman dapat diuraikan seperti hukuman ringan, hukuman sedang, hukuman berat.

Di sisi lain , Florina (2013), meyatakan pula bahwa kinerja meliputi beberapa aspek, yaitu quality of work (kualitas pekerjaan), Promptness (kecepatan), Initative (Prakarsa), Capability (kemmampuan), Communication (komunikasi). Sedangkan motivasi kerja, menurut Hasibuan (2003), memiliki beberapa tujuan diantaranya mendorong gairah dan semangat kerja karyawan, meningkatkan moral dan kepuasan kerja karyawan, meningkatkan produktivitas kerja

\section{RUMUSAN MASALAH}

Berdasarkan latar belakang penelitian yang telah dijelaskan diatas maka, dirumuskan masaalah sebagai berikut :

1. Sejauhmana pengaruh reward terhadap kinerja karyawan pada CV. Media Kreasi Bangsa.

2. Sejauhmana pengaruh reward terhadap motivasi karyawan pada CV. Media Kreasi Bangsa.

3. Sejauhmana pengaruh reward dan punishment secara simultan terhadap kinerja karyawan pada CV. Media Kreasi Bangsa.

4. Sejauhmana pengaruh punishment terhadap kinerja karyawan pada CV. Media Kreasi Bangsa.

5. Sejauhmana pengaruh punishment terhadap motivasi pada CV. Media Kreasi Bangsa.

6. Sejauhmana pengaruh reward dan punishment secara simultan terhadap 
motivasi karyawan pada CV. Media Kreasi Bangsa.

\section{TUJUAN PENELITIAN}

Tujuan dari Pengaruh Reward dan Punishment terhadap Kinerja dan Motivasi Karyawan Pada CV. Media Kreasi Bangsa ini adalah :

1. Mengetahui dan menganalisis pengaruh reward terhadap kinerja karyawan pada CV. Media Kreasi Bangsa.

2. Mengetahui dan menganalisis pengaruh reward terhadap motivasi karyawan pada CV. Media Kreasi Bangsa.

3. Mengetahui dan menganalisis reward dan punishment secara simultan terhadap kinerja karyawan pada CV. Media Kreasi Bangsa.

4. Mengetahui dan menganalisis pengaruh punishment terhadap kinerja karyawan pada CV. Media Kreasi Bangsa.

5. Mengetahui dan menganalisis pengaruh punishment terhadap motivasi karyawan pada CV. Media Kreasi Bangsa.

6. Mengetahui dan menganalisis reward dan punishment secara simultan terhadap motivasi karyawan pada CV. Media Kreasi Bangsa.

\section{MANFAAT PENELITIAN}

Sebagai bahan masukan bagi perusahaan berkaitan dengan kinerja SDM dengan menggunakan strategi reward dan punishment yang berpengaruh terhadap kinerja dan motivasi karyawan, dan diharapkan penelitian ini menjadi sumbangan pemikiran bagi perusahaan yang bersangkutan.

\section{KAJIAN TEORI}

\section{Reward}

Menurut Aktar (2012) Reward adalah suatu elemen penting untuk memotivasi karyawan untuk berkontribusi menuangkan ide inovasi yang paling baik untuk fungsi bisnis yang lebih baik dan meningkatkan kinerja perusahaan baik secara financial dan non-financial. Sistem penghargaan yang ditawarkan dan diberikan kepada karyawan meliputi (Siswanto, 2003):

1. Sistem Penghargaan Intrinsik

Sistem penghargaan intrinsik berisi penghargaan yang berasal dari respon individu terhadap pekerjaan itu sendiri (berasal dari satu transaksi antara satu individu dengan tugasnya, tanpa ikut serta pihak ketiga).

2. Sistem Penghargaan Ekstrinsik

Penghargaan ekstrinsik adalah kompensasi yang secara langsung disampaikan dan dikontrol oleh organisasi (pihak ketiga) serta bersifat lebih kasat mata (mudah dilihat).

\section{Punishment}

Menurut (Rivai, 2013), jenis-jenis Punishment dapat diuraikan sebagai berikut:

1. Hukuman ringan, dengan jenis :

a. Teguran lisan kepada karyawan yang bersangkutan.

b. Teguran tertulis.

c. Pernyataan tidak puas secara tidak tertulis.

2. Hukuman sedang, dengan jenis :

a. Penundaan kenaikan gaji yang sebelumnya telah direncanakan sebagaimana karyawan lainnya.

b. Penurunan gaji yang besarnya disesuaikan dengan peraturan perusahaan.

c. Penundaan kenaikan pangkat atau Promosi

3. Hukuman berat, dengan jenis :

a. Penurunan pangkat atau demosi. 
Adhitomo \& Ismi, pengaruh reward dan punishment terhadap kinerja dan motivasi ....

b. Pembebasan dari jabatan.

c.Pemberhentian kerja atas permintaan karyawan yang bersangkutan.

d. Pemutusan hubungan kerja sebagai karyawan di perusahaan

\section{Kinerja}

Manajemen kinerja menurut Ruky (2002) adalah suatu bentuk usaha kegiatan atau program yang diprakarsai dan dilaksanakan oleh pimpinan organisasi atau perusahaan untuk mengarahkan atau mengendalikan prestasi karyawan.

sedarmayanti dalam (Florina, 2013), meyatakan pula bahwa kinerja meliputi beberapa aspek, yaitu

1. Quality of work (kualitas pekerjaan)

2. Promptness (kecepatan)

3. Initative (Prakarsa)

4. Capability (kemmampuan)

5. Communication(komunikasi)

\section{Motivasi}

Motivasi menurut Purwanto dalam Pahlevi (2012), adalah "Usaha yang disadari untuk mempengaruhi tingkah laku seseorang agar tergerak hatinya untuk bertindak melakukan sesuatu yang mencapai hasil atau tujuan tertentu. Menurut islam dan ismail (2006), menunjukkan 6 faktor motivasi bagi karyawan:

1. Gaji tinggi

2. Kondisi kerja yang nyaman

3. Promosi

4. Kerja yang menantang

5. Keamanan kerja

6. penghargaan

\section{Kerangka Penelitian}

Kerangka pemikiran dibuat guna mempermudah pemahaman mengenai penelitian yang akan dilakukan. Adapun kerangka penelitian pada penelitian ini dijelaskan pada Gambar 1.

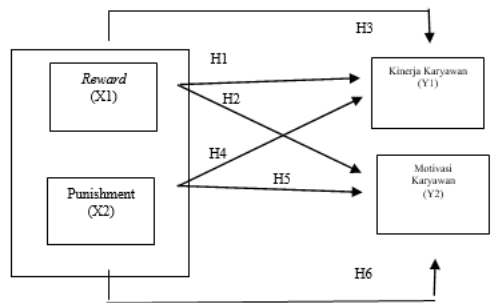

\section{Gambar 1 Kerangka Penelitian}

\section{METODE PENELITIAN}

\section{Desain/Jenis Penelitian}

Penelitian ini termasuk kedalam penelitian explanatory research, dengan metode analisis data (Statistik Deskriptif dan Statistik Inferensial). (Singarimbun dan Effendi, 2006), menjelaskan explanatory research yaitu penelitian yang digunakan untuk menjelaskan hubungan kausal antara variabel-variabel melalui pengujian hipotesa yang dirumuskan atau sering kali disebut sebagai penelitian penjelas

\section{Objek dan Ruang Lingkup Penelitian}

ruang lingkup dari penelitian ini adalah mencakup instansi penelitian yaitu objek seluruh karyawan CV. Media Kreasi Bangsa.

\section{Operasionalisasi Variabel}

Oprasionalisais variabel adalah suatu atribut atau sifat atau nilai dari orang, objek atau kegiatan yang mempunyai variasi tertentu yang ditetapkan oleh peneliti dan untuk dipelajari dan kemudian ditarik kesimpulan (Sugiyono, 2014). Pada penelitian ini terdapat dua variabel, yaitu variabel bebas (variabel indenpenden) dan variabel terikat (variabel dependen), yaitu:

1. Variabel bebas merupakan variabel yang mempengaruhi atau yang menjadi sebab perubahannya atau timbulnya variabel terikat. Dalam penelitian ini variabel bebas adalah reward (X1) dan punishment (X2). Adapun yang menjadi indikator reward yaitu sistem penghargaan intrinsik dan ekstrinsik sedangkan 
punishment yaitu hukuman ringan, sedang, berat.

2. Variabel terikat dalam penelitian ini yaiu kinerja karyawan (Y1) dengan indikator Quality of work (kualitas pekerjaan), Capability (kemampuan). Communication (komunikasi) dan motivasi sebagai (Y2) dengan indikator gaji tinggi, kondisi kerja yang nyaman, promosi, kerja yang menantang, keamanan kerja dan penghargaan.

\section{Populasi dan Sampel \\ Populasi}

Populasi yang digunakan dalam penelitian ini adalah seluruh tenaga kerja CV. Media Kreasi Bangsa. Populasi dalam penelitian ini berjumlah 200 tenaga kerja dan terdiri dari beberapa Departement yaitu HRGA HO, DC \& MD HO, PRODUKSI HO, F\&A HO, MARKETING HO, IT HO, OPERASIONAI, MAINTENANCE

\section{Sampel}

Sampel adalah sebagian dari populasi tersebut. Dalam penelitian ini menggunakan teknik Sampling Probability, menurut (Sugiyono, 2016) dimana sampel di ambil dengan menggunakan Proportionate Stratified Random Sampling. Teknik ini digunakan bila populasi mempunyai anggota/unsur yang tidak homogen dan berstrata secara porporsional. Dalam penelitian ini menggunakan pedoman tabel Krejcie dan Morgan. Teknik pengambilan sampel yang memberikan peluang yang sama bagi setiap unsur (anggota) populasi untuk dipilih menjadi anggota sampel. Krejcie dan Morgan, memiliki tingkat kesalahan $5 \%$ dan tingkat kepercayaan terhadap populasi sebesar $95 \%$. Presentase sampel disesuaikan dengan jumlah populasi, dimana semakin besar populasi semakin kecil prosentase sampel yang diambil (Sugiyono, 2008). dimana dengan sampel 200 jumlah populasi dapat di ambil sampel melalui pedoman Tabel
Krejcie dan Morgan di dapat 132 jumlah sampel.

\section{Jenis dan Sumber Data}

Adapun jenis data dan sumber data yang digunakan dalam penelitian ini berupa :

1. Data Primer

Data primer adalah sumber data yang langsung memberikan data kepada pengumpul data (Sugiyono, 2014). Adapun data primer dalam penelitian ini melalui penyebaran kuisioner dengan pihak-pihak yang berhubungan dengan penelitian ini

\section{Data Sekunder}

Data sekunder adalah data yang diperoleh secara tidak langsung dengan mempelajari literatur atau dokumen (Sugiyono, 2014). Dalam penelitian ini yang menjadi data sekunder berupa datadata dari perusahaan misalnya struktur organisasi perusahaan, dan dokumen lainnya yang mendukung penelitian ini

\section{Teknik Pengumpulan Data}

Adapun teknik pengumpulan data yang dilakukan dalam penelitian ini adalah :

1. Wawancara

Wawancara merupakan teknik pengumpulan data dimana pewawancara dalam mengumpulkan data mengajukan suatu pertanyaan kepada yang diwawancara (Sugiyono, 2014). Dalam penelitian ini peneliti mewawancarai HRGA Supervisor CV. Media Kreasi Bangsa.

2. Kuesioner (Angket)

Kuesioner merupakan teknik pengumpulan data yang dilakukan dengan cara memberi seperangkat pertanyaan atau pernyataan tertulis kepada responden untuk dijawab (Sugiyono, 2014), kuesioner dalam penelitian ini terdiri dari pertanyaan tertutup. Pertanyaan tertutup adalah dimana responden tinggal memilih salah alternatif dari jawaban yang 
Adhitomo \& Ismi, pengaruh reward dan punishment terhadap kinerja dan motivasi ....

telah tersedia. Dalam penelitian ini jawaban dari pertanyaan tertutup akan diukur menggunakan skala likert. Dalam skala likert variabel akan diukur dijabarkan menjadi indikator variabel, kemudian indikator tersebut dijadikan sebagai titik tolak untuk menyusun item-item instrumen yang dapat berupa pernaytaan atau pertanyaan.

1. Untuk jawaban SS, yaitu sangat setuju diberikan skor : 4

2. Untuk jawaban $S$, yaitu setuju

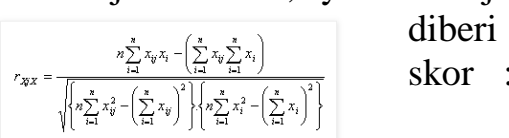

3. Untuk jawabanTS, yaitu tidak setuju diberi skor : 2

4. Untuk jawaban STS, yaitu sangat tidak setuju diberi skor : 1

3. Observasi

Observasi adalah studi yang dilakukan secara sengaja dan sistematis, terarah dan terencana pada tujuan tertentu dengan mengamati dan mencatat fenomenafenomena yang terjadi dalam suatu kelompok dengan mengacu pada syarat-syarat dan aturan penelitian ilmiah. Adapun observasi yang dilakukan peneliti dalam penelitian ini adalah dengan melakukan wawancara secara langsung dengan pihak yang terkait (HRGA Supervisor) dalam penelitian ini.

4. Dokumentasi

Dokumentasi adalah kumpulan dari dokumen-dokumen yang dapat memberikan keterangan-keterangan atau bukti yang berkaitan dengan proses pengumpulan dan pengelolaan dokumen secara sistematis. Adapun dokumentasi yang dilakukan peneliti dalam penelitian ini adalah dengan menyebarkan berupa kuesioner kepada karyawan CV. Media Kreasi Bangsa.

\section{HASIL DAN PEMBAHASAN}

\section{Validitas dan Reliabilitas}

\section{Uji Validitas}

Menurut Ghozali (2005), uji validitas digunakan untuk mengukur sah atau valid tidaknya suatu kuesioner. Suatu kuesioner dikatakan valid jika pertanyaan pada kuesioner mampu untuk mengungkapkan suatu yang akan diukur oleh kuesioner tersebut. Dalam uji validitas digunakan rumus :

Dimana: $\mathrm{Xj}=$ skor item ke-j untuk $\mathrm{j}=1,2, \ldots ., \mathrm{k}$

$\mathrm{X}=$ skor total keseluruhan item

$\mathrm{K}$ = banyaknya item

$\mathrm{n}=$ jumlah pengamatan

Tabel 1 Rekapitulasi hasil uji validitas instrumen penelitian Reward, Punishmemnt, Kinerja, Motivasi

\begin{tabular}{|l|l|l|l|l|}
\hline No & Reward & & & \\
\hline & X1 & r hitu & r tabel & Keterang \\
\hline $\mathbf{1}$ & Pertanyaa & 0,347 & 0,2353 & VALID \\
\hline $\mathbf{2}$ & Pertanyaa & 0,444 & 0,2353 & VALID \\
\hline $\mathbf{3}$ & Pertanyaa & 0,261 & 0,2353 & VALID \\
\hline $\mathbf{4}$ & Pertanyaa & 0,624 & 0,235 & VALID \\
\hline $\mathbf{5}$ & Pertanyaa & 0,563 & 0,2353 & VALID \\
\hline $\mathbf{6}$ & Pertanyaa & 0,594 & 0,2353 & VALID \\
\hline $\mathbf{7}$ & Pertanyaa & 0,584 & 0,2353 & VALID \\
\hline $\mathbf{8}$ & Pertanyaa & 0,586 & 0,2353 & VALID \\
\hline $\mathbf{9}$ & Pertanyaa & 0,439 & 0,2353 & VALID \\
\hline $\mathbf{1 0}$ & $\begin{array}{l}\text { Pertanyaa } \\
10\end{array}$ & 0,651 & 0,2353 & VALID \\
\hline $\mathbf{1 1}$ & $\begin{array}{l}\text { Pertanyaa } \\
11\end{array}$ & 0,503 & 0,2353 & VALID \\
\hline $\mathbf{1 2}$ & $\begin{array}{l}\text { Pertanyaa } \\
12\end{array}$ & 0,569 & 0,2353 & VALID \\
\hline $\mathbf{1 3}$ & $\begin{array}{l}\text { Pertanyaa } \\
13\end{array}$ & 0,619 & 0,2353 & VALID \\
\hline & Punishme & & & \\
\hline & X2 & r hitu & r tabel & Keterang \\
\hline
\end{tabular}




\begin{tabular}{|c|c|c|c|c|}
\hline 1 & Pertanyaa & 0,653 & 0,2353 & VALID \\
\hline 2 & Pertanyaa & 0,571 & 0,2353 & VALID \\
\hline 3 & Pertanyaa & 0,679 & 0,2353 & VALID \\
\hline 4 & Pertanyaa & 0,663 & 0,2353 & VALID \\
\hline 5 & Pertanyaa & 0,736 & 0,2353 & VALID \\
\hline 6 & Pertanyaa & 0,386 & 0,2353 & VALID \\
\hline 7 & Pertanyaa & 0,378 & 0,2353 & VALID \\
\hline 8 & Pertanyaa & 0,481 & 0,2353 & VALID \\
\hline \multirow[t]{3}{*}{9} & Pertanyaa & 0,704 & 0,2353 & VALID \\
\hline & Kinerja & & & \\
\hline & Y1 & r hitu & $r$ tabel & Keterang \\
\hline 1 & Pertanyaa & 0,664 & 0,2353 & VALID \\
\hline 2 & Pertanyaa & 0,521 & 0,2353 & VALID \\
\hline 3 & Perta & 0,767 & 0,2353 & VALID \\
\hline 4 & Per & 0,731 & 0,2353 & VALID \\
\hline 5 & Pert & 0,498 & 0,2353 & VALID \\
\hline 6 & Pertanyaa & 0,808 & 0,2353 & VALID \\
\hline 7 & Pertanyaa & 0,578 & 0,2353 & VALID \\
\hline 8 & Pertanyaa & 0,566 & 0,2353 & VALID \\
\hline 9 & Pertanyaa & 0,671 & 0,2353 & VALID \\
\hline 10 & $\begin{array}{l}\text { Pertanyaa } \\
10\end{array}$ & 0,617 & 0,2353 & \\
\hline 11 & $\begin{array}{l}\text { Pertanyaa } \\
11\end{array}$ & 0,728 & 0,2353 & VALID \\
\hline \multirow[t]{3}{*}{12} & $\begin{array}{l}\text { Pertanyaa } \\
12\end{array}$ & 0,542 & 0,2353 & VALID \\
\hline & Motivasi & & & \\
\hline & Y2 & r hitu & $r$ tabel & Keterang \\
\hline 1 & Pertanyaa & 0,403 & 0,2353 & VALID \\
\hline 2 & Pertanyaa & 0,595 & 0,2353 & VALID \\
\hline 3 & Pertanyaa & 0,730 & 0,2353 & VALID \\
\hline 4 & Pertanyaa & 0,718 & 0,2353 & VALID \\
\hline 5 & Pert & 0,782 & 0,2353 & VALID \\
\hline 6 & Pertanyaa & 0,698 & 0,2353 & VALID \\
\hline 7 & Pertanyaa & 0,577 & 0,2353 & VALID \\
\hline 8 & Pertanyaa & 0,526 & 0,2353 & VALID \\
\hline 9 & Pertanyaa & 0,637 & 0,2353 & VALID \\
\hline 10 & $\begin{array}{l}\text { Pertanyaa } \\
10\end{array}$ & 0,582 & 0,2353 & VALID \\
\hline 11 & $\begin{array}{l}\text { Pertanyaa } \\
11\end{array}$ & 0,641 & 0,2353 & VALID \\
\hline 12 & $\begin{array}{l}\text { Pertanyaa } \\
12\end{array}$ & 0,662 & 0,2353 & VALID \\
\hline
\end{tabular}

(Sumber : Pengolahan Data, 2017)

Berdasarkan pengolahan data pengujian validitas pada Tabel 1 diketahui bahwa pernyataan dalam variabel memenuhi syarat untuk bisa dianggap valid. Dikatakan valid apabila $\mathrm{r}$ hitung > 0.2787, maka dapat diproses lebih lanjut

\section{Uji Reliabilitas}

Reliabilitas (reliability) merupakan suatu pengukuran yang menunjukkan stabilitas dan konsistensi dari suatu instrumen yang mengukur suatu konsep dan berguna untuk mengakses "kebaikan" dari suatu pengukur (Jogiyanto, 2015). Pertanyaan dalam kuesioner dianggap reliabel, konsisten dan relevan terhadap variabel dalam penelitian jika batas nilai Alfha Cronbach's sebesar 0,6 terpenuhi

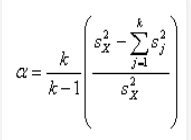

Dimana :

$s j^{2}=$ varians skor item ke $-\mathrm{j}$ dengan $\mathrm{j}-$ $1,2, \ldots, \mathrm{k}$

$\mathrm{k}$ = banyaknya item yang diujikan $s x^{2}=$ varians skor total keseluruhan item

Tabel 2 Rekapitulasi Hasil Uji Reliabilitas Reward, Punishmnet, Kinerja, Motivasi

\begin{tabular}{|l|l|l|}
\hline Variabel & $\begin{array}{l}\text { Cronbach's } \\
\text { Alpha }\end{array}$ & N \\
\hline Reward & 0,716 & 15 \\
\hline Punishment & 0,740 & 10 \\
\hline Kinerja & 0,757 & 13 \\
\hline Motivasi & 0,754 & 13 \\
\hline
\end{tabular}

(Sumber : Pengolahan Data, 2017)

Berdasarkan Tabel .2 diketahui bahwa keempat variabel dalam penelitian ini masing-masing memiliki nilai Cronbach's Alpha lebih besar dari 0.6 sehingga dapat disimpulkan bahwa alat ukur yang digunakan tersebut reliable, konsisten dan relevan sehingga layak untuk diproses lebih lanjut 
Adhitomo \& Ismi, pengaruh reward dan punishment terhadap kinerja dan motivasi ....

Metode Analisis Data

Statistik Deskriptif Statistik deskriptif digunakan untuk menganalisis data

dengan cara mendeskripsikan atau menggambarkan karakteristik data sampel yang telah terkumpul tanpa membuat kesimpulan yang berlaku umum atau generalisasi (Sujarweni, 2008).

Hasil analisis responden berdasarkan jenis kelamin, status, umur, pendidikan, masa bekerja dapat dilihat pada Tabel 2 berikut ini: 
Tabel 3 Statistik Deskriptif berdasarkan jenis kelamin, status, umur, masa bekerja, pendidikan terakhir

\begin{tabular}{|c|c|}
\hline $\begin{array}{l}\text { Karakteristik } \\
\text { Responden }\end{array}$ & Keterangan \\
\hline \multicolumn{2}{|l|}{$\begin{array}{l}\text { Jenis } \\
\text { Kelamin }\end{array}$} \\
\hline Laki-laki & $\begin{array}{l}89 \text { Responden } \\
(67,4 \%)\end{array}$ \\
\hline Perempuan & $\begin{array}{l}43 \text { Responden } \\
(32,6 \%)\end{array}$ \\
\hline \multicolumn{2}{|l|}{ Status } \\
\hline Menikah & $\begin{array}{l}48 \text { Responden } \\
(36,4 \%)\end{array}$ \\
\hline $\begin{array}{l}\text { Belum } \\
\text { Menikah }\end{array}$ & $\begin{array}{l}84 \text { Responden } \\
(63,6 \%)\end{array}$ \\
\hline \multicolumn{2}{|l|}{ Umur } \\
\hline$<20$ Tahun & $\begin{array}{l}10 \text { Responden } \\
(7,6 \%)\end{array}$ \\
\hline 21-30 Tahun & $\begin{array}{l}110 \text { Responden } \\
(83,3 \%)\end{array}$ \\
\hline 31-40 Tahun & $\begin{array}{l}12 \text { Responden } \\
(9,1 \%)\end{array}$ \\
\hline \multicolumn{2}{|l|}{ Pendidikan } \\
\hline SMP & $\begin{array}{l}6 \quad \text { Responden } \\
(4,5 \%)\end{array}$ \\
\hline SMU/SMK & $\begin{array}{l}90 \text { Responden } \\
(68,2 \%)\end{array}$ \\
\hline Diploma & $\begin{array}{l}12 \text { Responden } \\
(9,1 \%)\end{array}$ \\
\hline S1 (Sarjana) & $\begin{array}{l}24 \text { Responden } \\
(18,2 \%)\end{array}$ \\
\hline \multicolumn{2}{|l|}{$\begin{array}{l}\text { Masa } \\
\text { Bekerja }\end{array}$} \\
\hline$<1$ Tahun & $\begin{array}{l}104 \text { Responden } \\
(78,8 \%)\end{array}$ \\
\hline 1-2 tahun & $\begin{array}{l}16 \text { Responden } \\
(12,1 \%)\end{array}$ \\
\hline 3-4 Tahun & $\begin{array}{l}7 \quad \text { Responden } \\
(5,3 \%)\end{array}$ \\
\hline$>4$ Tahun & $\begin{array}{l}5 \quad \text { Responden } \\
(3,8 \%)\end{array}$ \\
\hline
\end{tabular}

(Sumber : Hasil Pengolahan Data, 2017)

\section{Uji Asumsi Klasik}

1. Uji Normalitas

Uji Normalitas bertujuan untuk menguji model regresi apakah variabel dependen dalam penelitian ini mempunyai distribusi normal atau tidak normal. Pengujian normalitas dapat diuji menggunakan kolmogorow-smirnov dengan perbandingan sig $>5 \%$ dapat diketahui bahwa berdistribusi normal, sedangkan sig $<5 \%$ dapat diketahui bahwa data tidak berdistribusi normal.

\section{Tabel 4 Hasil Uji Sampel K-S}

One-Sample Kolmogorov-Smirnov Test

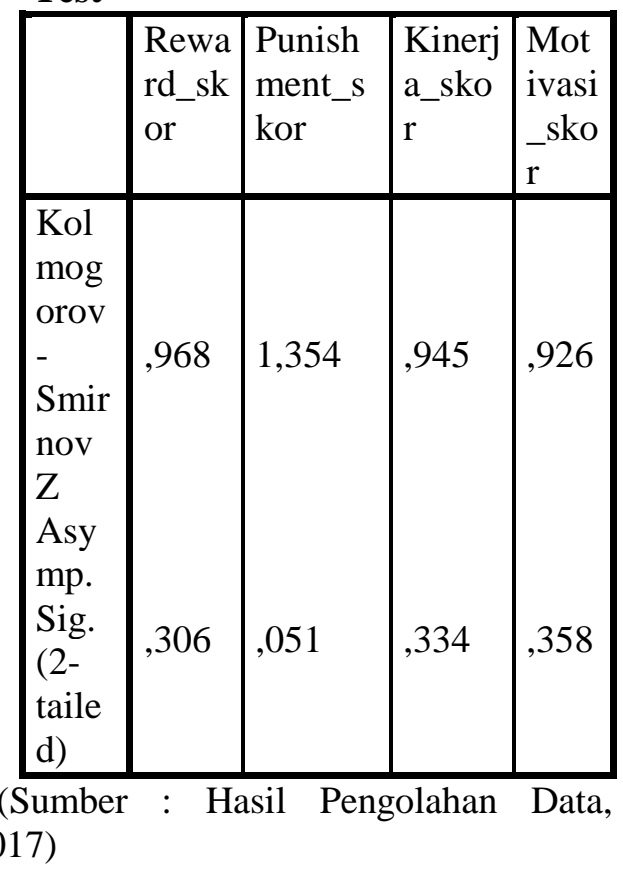

Berdasarkan Tabel 4 di atas dapat dilihat bahwa data sebanyak $132(\mathrm{~N}=132)$. Jika signifikan > 0,05 maka data berdistribusi normal, jika signifikan $<0,5$ maka data tidak berdistribusi normal (Sujarweni, 2015). Dalam penelitian ini data memiliki distribusi normal karena nilai "Asymp. Sig. (2-tailed)" memiliki tingkat Signifikansi $>0,05$. Signifikan data untuk reward adalah 0,306 maka lebih besar dari 0,05, data punishment adalah 0,051 maka lebih besar dari 0,05 , data kinerja adalah 0,334 maka lebih besar dari 0,05, data motivasi adalah 0,358 maka lebih 
Adhitomo \& Ismi, pengaruh reward dan punishment terhadap kinerja dan motivasi ....

besar dari 0,05. Jadi pada tabel OneSample Kolmogorov-Smirnov Test uji normalitas terpenuhi

2. Uji Multikolibieritas

Uji Multikolinieritas bertujuan untuk menguji apakah ada korelasi antar variabel independen/bebas. Model regresi yang baik seharusnya tidak ditentukan korelasi antar variabel bebas, jika ditemukan korelasi antar variabel bebas maka variabel-variabel tersebut tidak orthogonal atau terjadi kemiripan. Variabel orthogonal adalah korelasi nilai variabel antar sesama variabel independen/bebas bernilai nol. Multikolinearitas dapat dilihat dari nilai tolerance dan lawannya variance inflation factor (VIF).

\section{Tabel 5 Hasil Uji Multikolinearitas}

\begin{tabular}{|l|l|l|l|}
\hline \multirow{2}{*}{$\begin{array}{l}\text { Depende } \\
\mathrm{n}(\mathrm{Y})\end{array}$} & \multirow{2}{*}{$\begin{array}{l}\text { Independe } \\
\mathrm{n}(\mathrm{X})\end{array}$} & \multicolumn{3}{|l|}{$\begin{array}{l}\text { Colinearity } \\
\text { Statistics }\end{array}$} & $\begin{array}{l}\text { Toleranc } \\
\mathrm{e}\end{array}$ & $\mathrm{VIF}$ \\
\hline \multirow{3}{*}{ Kinerja } & Reward & 0,941 & $\begin{array}{l}1,06 \\
2\end{array}$ \\
\cline { 3 - 4 } & $\begin{array}{l}\text { Punishme } \\
n t\end{array}$ & 0,941 & $\begin{array}{l}1,06 \\
2\end{array}$ \\
\hline \multirow{4}{*}{ Motivasi } & Reward & 0,941 & $\begin{array}{l}1,06 \\
2\end{array}$ \\
\cline { 2 - 4 } & $\begin{array}{l}\text { Punishme } \\
n t\end{array}$ & 0,941 & $\begin{array}{l}1,06 \\
2\end{array}$ \\
\hline
\end{tabular}

Sumber : Hasil Pengolahan Data, 2017)

Berdasarkan Tabel 5 diketahui bahwa hasil uji multikolinieritas menunjukkan reward dan punishment memiliki nilai tolerance sebesar 0,941. Hal ini menunjukkan tidak ada variabel independen yang memiliki nilai tolerance kurang dari 0,10 yang berarti tidak ada kolerasi antar variabel independen.hasil perhitungan nilai Variance Inflation Factor (VIF) juga menunjukkan hasil sebesar 1,062 untuk reward dan punishment. Jika nilai VIF yang dihasilkan diantara 1-10 maka tidak terjadi multikolinearitas (Sujarweni, 2015). Dalam penelitian ini dimana tidak ada satu variabel independen yang memiliki nilai VIF lebih dari 10. Jadi dapat disimpulkan bahwa tidak ada multikolinieritas antar variabel independen dalam model regresi.

3. Uji Heteroskedastisitas

Uji Heteroskedastisitas bertujuan untuk mengetahui apakah dalam model regresi terjadi ketidaksamaan variance dari residual satu pengamatan ke pengamatan lainnya. Jika variance tetap dalam pengujian tersebut maka terjadi homoskedastisitas dan akan mmenjdi problem heteroskedastisitas jika berbeda. Model regresi yang baik adalah tidak terjadi heteroskedastisitas dalam model regresi tersebut. Beberapa cara yang digunakan untuk melihat ada atau tidaknya heteroskedastisitas yaitu melihat nilai prediksi dependen Uji gletjer

\section{Tabel 6 Hasil Uji Heterokedastisitas}

\begin{tabular}{|l|l|l|}
\hline $\begin{array}{l}\text { Dependen } \\
(\mathrm{Y})\end{array}$ & $\begin{array}{l}\text { Independen } \\
(\mathrm{X})\end{array}$ & Signifikan \\
\hline \multirow{2}{*}{ Kinerja } & Reward & 0,569 \\
\cline { 2 - 3 } & Punishment & 0,787 \\
\hline \multirow{2}{*}{ Motivasi } & Reward & 0,186 \\
\cline { 2 - 3 } & Punishment & 0,107 \\
\hline
\end{tabular}

(Sumber : Hasil Pengolahan Data, 2017)

Berdasarkan Tabel 6 diketahui hasil ditampilkan bahwa variabel independent yaitu X1 (reward) dengan tingkat signfikan sebesar 0,569 dan X2 (Punihmnet) dengan tingkat signifikan sebesar 0,787 serta variabel independent yaitu X1 (reward) dengan tingkat signfikan sebesar 0,186 dan X2 (Punishmnet) dengan tingkat signifikan sebesar 0,107 maka varibel >0,05 (Sujarweni, 2015). Sehingga dapat 
disimpulkan bahwa model regresi tidak mengandung adanya heterokesdastisitas.

\section{Uji Autokorelasi}

Menurut

Priyatno

(2012), Autokorelasi adalah:"Autokorelasi adalah keadaan di mana pada model regresi ada korelasi antara residual pada periode tertentu $\mathrm{t}$ dengan residual pada periode sebelumnya (t-1), model regresi yang baik adalah yang tidak terdapat masalah autokorelasi. Mendeteksi autokorelasi dengan menggunakan nilai Durbin Watson dibandingkan dengan Tabel Durbin Watson $(d l$ dan $d u)$. Kriteria jika $d u<\mathrm{d}$ hitung $<4-d u$ maka tidak terjadi autokorelasi (Sujarweni, 2015).

\section{Tabel 7 Hasil Uji Autokorelasi}

\begin{tabular}{|c|c|c|c|c|}
\hline $\begin{array}{l}\text { Depen } \\
\text { den } \\
(Y)\end{array}$ & $\begin{array}{l}\text { Indepen } \\
\text { den }(X)\end{array}$ & $\begin{array}{l}\text { Durb } \\
\text { in- } \\
\text { Wats } \\
\text { on }\end{array}$ & $\begin{array}{l}\text { Tabel } \\
\text { Durb } \\
\text { in- } \\
\text { Wats } \\
\text { on } \\
(\mathrm{du})\end{array}$ & 4-du \\
\hline \multirow{2}{*}{$\begin{array}{l}\text { Kinerj } \\
\text { a }\end{array}$} & Reward & \multirow[b]{2}{*}{1,815} & \multirow{2}{*}{1,746} & \multirow{2}{*}{$\begin{array}{l}2,25 \\
4\end{array}$} \\
\hline & $\begin{array}{l}\text { Punish } \\
\text { ment }\end{array}$ & & & \\
\hline \multirow{2}{*}{$\begin{array}{l}\text { Motiva } \\
\text { si }\end{array}$} & Reward & \multirow[b]{2}{*}{1,986} & \multirow{2}{*}{1,746} & \multirow{2}{*}{$\begin{array}{l}2,25 \\
4\end{array}$} \\
\hline & $\begin{array}{l}\text { Punish } \\
\text { ment }\end{array}$ & & & \\
\hline
\end{tabular}

(Sumber : Hasil Pengolahan Data, 2017)

Berdasarkan Tabel 7 ditas diketahui bahwa Durbin-Watson 1,815 dan 1,986. Jika nilai du $<$ dw $<$ 4-du maka tidak terjadi autokorelasi (Sujarweni, 2015). pada tabel diatas dengan variabel dependen kinerja terdapat $\mathrm{dw}=1,815$ dengan jumlah sampel $\mathrm{N}=132$ dan jumlah variabel independen $2 \quad(\mathrm{~K}=2)$ maka diperoleh nilai $\mathrm{du}=1,745$ (pada tabel Durbin Watson). Nilai 1,746 < 1,815 < 2,254. Sedangkan variabel dependen motivasi terdapat $\mathrm{dw}=1,986$ dengan jumlah sampel $\mathrm{N}=132$ dan jumlah variabel dependen $2 \quad(\mathrm{~K}=2)$ maka diperoleh nilai $\mathrm{du}=1,746$ (pada tabel
Durbin Watson). Nilai $1,745<1,986<$ 2,254. Maka dapat disimpulkan tidak terjadi autokorelasi

\section{Analisis Regresi Linier Berganda}

Menurut Priyatno (2014), analisis ini digunakan untuk mengetahui pengaruh hubungan secara linier. Dalam penelitian ini peneliti menggunakan teknik analisa Regresi Linear Berganda untuk menguji kebenaran hipotesa, yaitu reward dan punishment berpengaruh terhadap kinerja dan motivasi karyawan CV. Media Kreasi Bangsa

$$
Y^{\prime}=a+b_{1} X_{1}+b_{2} X_{2}+\ldots . .+b_{n} X_{n}
$$

Keterangan:

$\mathrm{Y}^{\prime}=$ Nilai $\mathrm{Y}$

$\mathrm{X} 1=\mathrm{V}$ ariabel bebas 1

$\mathrm{X} 2=$ Variabel bebas 2

b1 $=$ koefisien regresi variabel bebas

b2=koefisien regresi variabel bebas

a. Konstanta dengan variabel dependen kinerja memiliki nilai sebesar 7,719 yang berarti bahwa jika variabel reward (X1), punishment $(\mathrm{X} 2)$ bernilai 0 , maka variabel kinerja memiliki nilai sebesar 7,719.

b. Konstanta dengan variabel dependen motivasi memiliki nilai sebesar 4,590 yang berarti bahwa jika variabel reward (X1), punishment (X2) bernilai 0 , maka variabel kiberja memiliki nilai sebesar 4,590

c. Koefesien regresi dengan variabel dependen kinerja memiliki nilai pada variabel reward 2,363 yang menunjukkan bahwa variabel ini berpengaruh positif dan signifikan.

d. Koefesien regresi dengan variabel dependen kinerja memiliki nilai pada variabel punishment 5,309 yang menunjukkan bahwa variabel ini berpengaruh positif dan signifikan.

e. Koefesien regresi dengan variabel dependen motivasi memiliki nilai pada variabel reward 4,289 yang 
Adhitomo \& Ismi, pengaruh reward dan punishment terhadap kinerja dan motivasi ....

menunjukkan bahwa variabel ini berpengaruh positif dan signifikan.

g. menunjukkan bahwa variabel ini berpengaruh positif dan signifikan.

h. Hasil Uji $R$ Square sebesar 0,247 dan 0,520 yang berarti variabel kinerja dan motivasi dipengaruhi sebesar $76,7 \%$ f. Koefesien regresi dengan variabel dependen motivasi memiliki nilai pada variabel punishment 3,587 yang oleh variabel reward dan punishment sementara sisanya sebesar $23,3 \%$

i. dipengaruhi oleh variabel lain yang tidak diteliti dalam penelitian ini.

Tabel 8 Hasil Uji Regresi Linear Berganda

\begin{tabular}{|c|c|c|c|c|c|}
\hline Dependen (Y) & $\begin{array}{l}\text { Independent } \\
\text { (X) }\end{array}$ & B & $\mathrm{T}$ & Sig & Pengaruh \\
\hline \multirow{3}{*}{ Kinerja } & Reward & 0,202 & 2,363 & 0,020 & $\begin{array}{l}\text { Positif } \\
\text { dan } \\
\text { signifikan }\end{array}$ \\
\hline & Punishment & 0,757 & 5,309 & 0,000 & \begin{tabular}{|l|} 
Positif \\
dan \\
signifikan
\end{tabular} \\
\hline & (Constant) & 7,719 & & & \\
\hline \multirow{3}{*}{ Motivasi } & Reward & 0,409 & 4,289 & 0,000 & $\begin{array}{l}\text { Positif } \\
\text { dan } \\
\text { Signifikan }\end{array}$ \\
\hline & Pinishment & 0,570 & 3,587 & 0,000 & $\begin{array}{l}\text { Positif } \\
\text { dan } \\
\text { signifikan }\end{array}$ \\
\hline & (Constant) & 4,590 & & & \\
\hline $\begin{array}{l}\text { Dependen Kinerja } \\
\text { F hitung } \\
\text { t table } \\
\text { F table } \\
\text { R } \\
\text { R Square }\end{array}$ & \multicolumn{2}{|l|}{$\begin{array}{l}=21,162 \\
=1,65666 \\
=3,07 \\
=0,497 \\
=0,247\end{array}$} & $\begin{array}{l}\text { Dependen } \\
\text { Motivasi } \\
\text { F hitung } \\
\text { t table } \\
\text { F table } \\
\text { R } \\
\text { R Square }\end{array}$ & $\begin{array}{l}=20,557 \\
=1,65666 \\
=3,07 \\
=0,721 \\
=0,520\end{array}$ & \\
\hline Adjusted R Square & $=0,235$ & & $\begin{array}{l}\text { Adjusted } \\
\text { R Square }\end{array}$ & $=0,512$ & \\
\hline
\end{tabular}

(Sumber : Hasil Pengolahan Data, 2017) 


\section{Uji t Parsial}

\section{Tabel 9 Hasil Uji t (Parsial}

\begin{tabular}{|l|l|l|l|}
\hline $\begin{array}{l}\text { Dependen } \\
(\mathrm{Y})\end{array}$ & $\begin{array}{l}\text { Independent } \\
(\mathrm{X})\end{array}$ & $\begin{array}{l}\mathrm{t} \\
\text { hitung }\end{array}$ & $\mathrm{t}$ table \\
\hline \multirow{2}{*}{ Kinerja } & Reward & 2,363 & 1,65666 \\
\cline { 2 - 4 } & Punishment & 5,309 & 1,65666 \\
\hline (Constant) & Reward & 1,563 & \\
\hline \multirow{2}{*}{ Motivasi } & Punishment & 3,589 & 1,65666 \\
\hline \multicolumn{2}{|l|}{ (Constant) } & 0,834 & 1,65666 \\
\hline
\end{tabular}

(Sumber : Hasil Pengolahan Data,2017)

Uji hipotesis yang digunakan dalam penelitian ini adalah uji t Parsial. Uji t Parsial dalam analisis regresi linear berganda bertujuan untuk menguji variabel independen (X) yang secara parsial berpengaruh terhadap variabel dependen (Y). Diketahui jika: Nilai sig $<0,05$ maka dapat disimpulkan bahwa variabel independen $(\mathrm{X})$ berpengaruh signifikan terhadap variabel dependen (Y) dan jika nilai sig > 0,05 maka dapat disimpulkan bahwa varaibel independen (X) tidak berpengaruh signifikan terhadap variabel dependen (Y) (Sujarweni, 2015).

Berdasarkan Tabel 9 diketahui Uji t pada varaibel reward memiliki nilai $\mathrm{t}$ hitung $(2,363)>\mathrm{t}$ tabel $(1,65666)$ yang berarti terdapat pengaruh secara parsial terhadap variabel kinerja. Uji t pada varaibel punishment memiliki nilai t hitung $(5,309)$ $>\mathrm{t}$ tabel $(1,65666)$ yang berarti terdapat pengaruh secara parsial terhadap variabel kinerja. Uji t pada varaibel reward memiliki nilai $\mathrm{t}$ hitung $(4,289)>\mathrm{t}$ tabel $(1,65666)$ yang berarti terdapat pengaruh secara parsial terhadap variabel motivasi. Uji $t$ pada varaibel punishment memiliki nilai t hitung $(3,587)>\mathrm{t}$ tabel $(1,65666)$ yang berarti terdapat pengaruh secara parsial terhadap variabel motivasi

\section{Uji F Simultan}

Menurut Ghozali dalam Regina, (2010), uji $\mathrm{F}$ digunakan untuk mengetahui tingkat signifikan pengaruh variabel-variabel independen secara besama-sama (simultan) terhadap variabel dependen.

\section{Tabel 10 Hasil Uji F (Simultan)}

\begin{tabular}{|l|c|c|}
\hline \multirow{2}{*}{ Dependen (Y) } & df & \multirow{2}{*}{$\mathrm{F}$} \\
\hline \multirow{3}{*}{ Kinerja } & 2 & \multirow{2}{*}{21,162} \\
\cline { 2 - 2 } & 129 & \\
\cline { 2 - 2 } & 131 & \\
\hline \multirow{3}{*}{ Motivasi } & 2 & \multirow{2}{*}{20,557} \\
\cline { 2 - 2 } & 129 & \\
\cline { 2 - 2 } & 131 & \\
\hline
\end{tabular}

(Sumber : Hasil Pengolahan Data,2017)

Berdasarkan Tabel 10 diketahui hasil Uji diperoleh nilai $\mathrm{F}$ hitung $(21,162)>$ $\mathrm{F}$ tabel $(3,07)$ yang berarti variabel reward dan punishment berpengaruh secara simultan terhadap kinerja karyawan. Hasil Uji diperoleh nilai $\mathrm{F}$ hitung $(20,557)>\mathrm{F}$ tabel $(3,07)$ yang berarti variabel reward dan punishment berpengaruh secara simultan terhadap motivasi karyawan.

\section{SIMPULAN DAN SARAN}

\section{Simpulan}

Berdasarkan hasil penelitian mengenai pengaruh reward dan punishment terhadap kinerja dan motivasi karyawan pada CV. Media Kreasi Bangsa, dapat ditarik kesimpulan yang sesuai dengan perumusan masalah sebagai berikut:

1. Hasil penelitian menunjukkan adanya pengaruh reward yang positif dan signifikan terhadap kinerja karyawan pada CV. Media Kreasi Bangsa. Berdasarkan uji regresi yang telah penulis lakukan menunjukkn bahwa hasil perhitungan $t$ hitung $(2,363)$ lebih besar dari $\mathrm{t}$ tabel $(1,65)$ dengan 
tingkatsignifikan $\mathrm{t}$ sebesar 0,020 dan nilai alpha 0,05 . Karena nilai signifikan $\mathrm{t}<$ nilai alpha $(0,020<$ $0,05)$.

2. Hasil penelitian menunjukkan adanya pengaruh reward yang positif dan signifikan terhadap motivasi karyawan pada CV. Media Kreasi Bangsa. Berdasarkan uji regresi yang telah penulis lakukan menunjukkn bahwa hasil perhitungan $t$ hitung $(4,289)$ lebih besar dari $\mathrm{t}$ tabel $(1,65)$ dengan tingkatsignifikan $\mathrm{t}$ sebesar 0,000 dan nilai alpha 0,05 . Karena nilai signifikan $\mathrm{t}<$ nilai alpha $(0,000<$ $0,05)$.

3. Hasil penelitian menunjukkan adanya pengaruh reward dan punishment secara simultan terhadap kinerja karyawan pada CV. Media Kreasi Bangsa. Berdasarkan uji regresi yang telah penulis lakukan menunjukkn bahwa hasil perhitungan Fhitung $(21,162)$ lebih besar dari F tabel $(3,07)$.

4. Hasil penelitian menunjukkan adanya pengaruh punishment yang positif dan signifikan terhadap kinerja karyawan pada CV. Media Kreasi Bangsa. Berdasarkan uji regresi yang telah penulis lakukan menunjukkn bahwa hasil perhitungan thitung $(5,309)$ lebih besar dari $t$ tabel $(1,65)$ dengan tingkatsignifikan $\mathrm{t}$ sebesar 0,000 dan nilai alpha 0,05 . Karena nilai signifikan $\mathrm{t}<$ nilai alpha $(0,000<$ $0,05)$.

5. Hasil penelitian menunjukkan adanya pengaruh punishment yang positif dan signifikan terhadap motivasi karyawan pada CV. Media Kreasi Bangsa. Berdasarkan uji regresi yang telah penulis lakukan menunjukkn bahwa hasil perhitungan thitung $(3,587)$ lebih besar dari t tabel $(1,65)$ dengan tingkatsignifikan t sebesar 0,000 dan nilai alpha 0,05 . Karena nilai signifikan $\mathrm{t}<$ nilai alpha $(0,000<$ $0,05)$.

6. Hasil penelitian menunjukkan adanya pengaruh reward dan punishment secara simultan terhadap motivasi karyawan pada CV. Media Kreasi Bangsa. Berdasarkan uji regresi yang telah penulis lakukan menunjukkn bahwa hasil perhitungan Fhitung $(20,557)$ lebih besar dari $\mathrm{F}$ tabel $(3,07)$.

\section{Saran}

Berdasarkan kesimpulan yang diperoleh dari hasil penelitian, maka dapat dikemukakan beberapa saran yaitu:

\section{Perusahaan}

1. Reward yang telah diberikan oleh perusahaan kepada karyawan telah diterapkan dengan baik seperti best employee dan best store. Akan tetapi dalam rangka untuk lebih memaksimalkan kinerja dan motivasi karyawan, hendaknya pihak perusahaan harus mampu bersifat obyektif terhadap setiap kinerja karyawan yang ditunjukkan. Hal ini bertujuan untuk membuat persaingan yang sehat sehingga setiap karyawan akan berlomba untuk lebih meningkatkan kinerjanya agar mendapatkan reward dari perusahaan.

2. Punishment yang berlaku di dalam CV. Media Kreasi bangsa telah berdampak pada kinerja dan motivasi karyawan. Namun pada realisasinya hendaknya perusahaan dapat lebih mensosialisasikan makna dari pemberian punishment kepada karyawannya. Perusahaan harus menciptakan pola pikir kepada karyawan bahwa pemberian punishment menjadi suatu alat untuk mengontrol setiap perilaku karyawan untuk tidak melakukan kelalaian atau kesalahan dalam pekerjaan dan terpacu menjadi 
lebih baik lagi dalam meningkatkan kinerjanya.

3. Agar reward dan punishment berjalan dengan baik maka perusahaan hendaknya menyusun terlebih dahulu program reward dan punishment secara cermat, sehingga program dan kebijakan tersebut tidak hanya menjadi dokumen tertulis saja, tetapi diterapkan atau diimplementasikan kepada karyawan CV. Media Kreasi Bangsa.

4. Perusahaan hendaknya benar-benar menerapkan proses-proses manajemen dengan baik, sebab reward dan punishment harus berjalan berdasarkan pada sistem manajemen yang mencakup pada peraturan manajemen, struktur dan prosedur untuk perencanaan dan kontrol yang baik dengan organisasi dan manajemen yang baik.

5. Semakin baik penerapan reward dan punishment, maka semakin baik pula kinerja dan motivasi karyawan terhadap perusahaan, sehingga diharapkan perusahaan lebih memperhatikan penerapan reward dan punishment untuk meningkatkan kinerja dan motivasi karyawan CV. Media Kreasi Bangsa.

\section{Penelitian Selanjutnya}

Perlu dilakukan penelitian lebih lanjut mengenai reward dan punishmnet pada CV. Media Kreasi Bangsa dengan menggunakan faktor-faktor lain selain yang telah diteliti pada penelitian ini, contoh dengan menggunakan metode lain seperti Structural Equation Modeling , Analisis Faktor yang mempengaruhi reward dan punishmnet dan dapat melakukan penelitian pada responden yang berbeda. Dan untuk peneliti yang akan datang disarankan juga untuk mencari ruang lingkup populasi yang berbeda dan lebih luas dari populasi dalam penelitian ini, sampel yang digunakan sebaiknya juga lebih banyak dari pada sampel dalam penelitian ini.

\section{Keterbatasan}

Pada kenyataanya penelitian ini masih memiliki beberapa keterbatasan. Dengan adanya keterbatasan ini, peneliti berharap dapat dilakukan pebaikan untuk penelitian dimasa yang akan datang.Adapun keterbatasan dalam penelitian ini yaitu:Penelitian ini hanya fokus pada 4 variabel saja dengan 2 variabel independen dan 2 variabel dependen sehingga untuk kedepannya dapat menambah variabel dan jumlah sampel yang lebih banyak dari penulis untuk menambah pengetahuan.

\section{Daftar Pustaka}

Arikunto, S. (2006). Prosedur Penelitian Suatu Pendekatan Praktik. Jakarta: PT. Rineka Cipta.

Febrianti, M. \&. (2014). Pengaruh Reward dan Punishment Terhadap Motivasi Kerja Serta Dampaknya Terhadap Kinerja (Studi pada Karyawan PT. Panin Indonesia Jakarta). Jurnal Administrasi Bisnis (JAB) Vol.12, No 1.

Januar, H. (2015). Pengaruh Ekstrinsik Reward dan Intrinsik Reward Terhadap Employee Performance: Telaah Pada PT XYZ. Ultima Management Vol 7. No.1.

Morgan, K. a. (1970). Determining Sample Size For Reserach Activities, Educational and Psychological Meansurement.

Pratama. (2015). Pengaruh Reward dan Punishment Terhadap Motivasi Kerja Karyawan Glodia Camilan Malang. e-Jurnal Riset Manajemen .

Pratama, U. \&. (2015). Pengaruh Imbalan dan Hukuman Terhadap Kepuasan Kerja dan Kinerja Karyawan (Studi Pada 
Adhitomo \& Ismi, pengaruh reward dan punishment terhadap kinerja dan motivasi ....

Karyawan Departement Statistik Bank Indonesia Jakarta). Jurnal Administrasi Bisnis (JAB)|Vol. 22 No. 1.

Reksohadiprojo, Y. (2001). Pengaruh Reward dan Punishment. Jakarta: Penerbit Rineka Cipta.

Sari. (2014). Pengaruh Komunikasi Internal, Reward dan Punishmnet Terhadap Motivasi

Siahaan. (2016). Pengaruh Rewad dan Punishment Terhadap Disiplin Kerja Karyawan Pada PT. Telkom Indonesia Regional Medan. Skripsi.

Sugiyono. (2016). Metode Penelitian Manajemen. Bandung: Penerbit Alfabeta.

Sujarweni. (2015). SPSS Untuk Penelitian . Yogyakarta: Pustaka Baru Press.

Syahril, N. (2016). Pengaruh Reward Ekstrinsik \& Intrinsik Terhadap Kinerja Dengan Kepuasan Kerja Sebagai Variabel
Kerja Karyawan di BPR Nur Semesta Indah Kencong Kabupaten Jember. Jurnal Ekonomi dan Bisnis.

Siahaan. (2013). Pengaruh Reward dan Punishmnet Terhadap Disiplin Kerja Karyawan Pada PT. Perkebunan Nusantara III Rambutan. Jurnal Ilmiah Business Progress.

Intervening. Jurnal Riset Manajemen Vol. 3, No. 1.

Wei, Y. (2014). The impact of Positive Reinforcement on Employees' Performance in Organizations. American Journal of Industrial and Business Management.

Yavarzadeh, R. (2015). The Impact Of Reward System On Human Resource Productivity In Chain Stores (A Case Study On Bama Chain Stores, Mashhad, Iran. United Kingdom Vol. III, Issue 11 ISSN 23480386. 